Pain Physician. 2004;7:365-375, ISSN 1533-3159

\title{
Managing Phantom Pain
}

\author{
Laxmaiah Manchikanti, MD, and Vijay Singh, MD
}

Since the first medical description of post-amputation phenomena reported by Ambrose Paré, persistent phantom pain syndromes have been well recognized. However, they continue to be difficult to manage. The three most commonly utilized terms include phantom sensation, phantom pain, and stump pain.

Phantom limb sensation is an almost universal occurrence at some time during the first month following surgery. However, most phantom sensations generally resolve after two to three years without treatment, except in the cases where phantom pain develops. The incidence of phantom limb pain has been reported to vary from $0 \%$ to $88 \%$. The incidence of phantom limb pain increases with more proximal amputations. Even though phantom pain may diminish with time and eventually fade away, it has been shown that even two years after amputation, the incidence is almost the same as at onset. Consequently, almost $60 \%$ of patients continue to have phantom limb pain after one year. In addition, phantom limb pain may also be associated with multiple pain problems in other areas of the body. The third symptom, stump pain, is located in the stump itself.

The etiology and pathophysiological mechanisms of phantom pain are not clearly defined. However, both peripheral and central neural mechanisms have been described, along with superimposed psychological mechanisms.

Literature describing the management of phantom limb pain or stump pain is in its infancy. While numerous treatments have been described, there is little clinical evidence supporting drug therapy, psychological therapy, interventional techniques or surgery.

This review will describe epidemiology, etiology and pathophysiological mechanisms, risk factors, and treatment modalities. The review also examines the effectiveness of various described modalities for prevention, as well as management of established phantom pain syndromes.

Keywords: Phantom pain, phantom sensation, stump pain, drug therapy, neural blockade
Persistent phantom pain syndromes are difficult to manage, leading to frustration of physicians and patients alike. Phantom sensation or pain is the persistent perception that a body part exists or is painful after it has been removed by amputation or trauma. Ambrose Paré $(1,2)$, a french military surgeon, provided the first medical description of postamputation phenomena. He noticed, as early as 1551, that amputees may complain of severe pain in the missing limb a long time after amputation. Civil War surgeon, Silas Weir Mitchell (3) in 1871 popularized the concept of phantom limb pain and coined the term phantom limb with publication of a long-term study on the fate of Civil War amputees. However, Herman Melville immortalized phantom limb pain in

From Pain Management Center of Paducah, Paducah, Kentucky, and Pain Diagnostic Associates, Niagara, Wisconsin. Address Correspondence: Laxmaiah Manchikanti, MD, 2831 Lone Oak Road, Paducah, Kentucky 42003

E-mail: drm@apex.net

Funding: There was no external funding in preparation of this manuscript.

Conflict of Interest: None
American literature, with graphic descriptions of Captain Ahab's phantom limb in Moby Dick.

Phantom sensation, phantom pain, and stump pain are the three most commonly utilized terms. Phantom sensations may occur in any part of the body but are most often described in the extremities (4-11).

\section{EPIDEMIOLOGY}

Phantom limb sensation in $85 \%$ to $98 \%$ of amputees is seen in the first 3 weeks after amputation (12), whereas in a small proportion of the patients (approximately $8 \%$ ), phantom limb sensation may not occur until 1 to 12 months following amputation (13). Most phantom sensations generally resolve after 2 to 3 years without treatment, except in the cases where phantom pain develops. Phantom limb sensation is strongest in amputations above the elbow and weakest in amputations below the knee (14), and is more frequent in the dominant limb of double amputees (15).

The incidence of phantom limb pain has been reported to vary from $0 \%$ to $88 \%$ (16-32). Prospective evaluations
$(31,37)$ suggest that in the year after amputation, $60 \%$ to $70 \%$ of amputees experience phantom limb pain, but it diminishes with time $(14,31)$. The incidence of phantom limb pain increases with more proximal amputations. The reports of phantom limb pain after hemipelvectomy ranged from $68 \%$ to $88 \%$ and following hip disarticulation, $40 \%$ to $88 \%$ (28, 30). However, wide variations exist with reports of phantom limb pain after lower extremity amputation as high as $72 \%$ (21) and as low as 51\% after upper limb amputation (22). Further, $0 \%$ prevalence was reported in below knee amputations compared to $19 \%$ in above the knee amputations (30). Phantom limb pain has been reported to occur as early as one week after amputation and as late as 40 years after amputation $(4,33,34)$. Phantom pain may diminish with time and eventually fade away. However, some prospective studies indicate that even 2 years after amputation, the incidence is almost the same as at onset $(31,37)$. It is reported that almost $60 \%$ of patients continue to have phantom limb pain $(24,31)$ after one year, whereas in the first month following amputation, $85 \%$ to $97 \%$ of pa- 
tients experience phantom limb pain (24, 29, 30). While phantom limb pain may begin months to years after an amputation, pain starting after one year following amputation occurs in fewer than 10\% of patients (4).

Stump pain is reported in up to $50 \%$ of amputees $(16,18,21-23,35-37)$. Reports showed that $50 \%$ to $88 \%$ of the patients with phantom pain also reported stump pain $(25,30)$.

Phantom limb pain is also associated with multiple pain problems in other areas of the body, with reports indicating headache or pain in joints in 35\% of the patients, sore throat in $28 \%$ of the patients, abdominal pain in $18 \%$, and back pain in $13 \%$ (38).

\section{ETIOLOGY}

\section{Pathophysiology}

Among phantom sensations, phantom pain, and stump pain, phantom senlieved that, throughout life an individual's body image develops from proprioceptive, tactile, and visual inputs (39). Thus, once a cortical representation of the body image is established, it is unchanged following limb amputation $(4,7)$.

The etiology and pathophysiological mechanisms of phantom pain are not clearly defined. However, both peripheral and central neuronal mechanisms are likely to occur. In addition, psychological mechanisms have been proposed. However, none of the theories independently, fully explain the clinical characteristics of this condition.

Nikolajsen and Jensen (40) described several clinical observations (Table 1) that suggest that mechanisms in the periphery, either in the stump or in the central parts of sectioned primary afferents may play a role in the phantom limb percept. Exsations are the easiest to explain. It is be-

perimental support has been provided for these clinical observations. Peripherally, spontaneous and abnormal evoked activity following mechanical or neurochemical stimulation are observed in nerve-end neuromas $(41,42)$. This increased activity is assumed to be the result of a novel expression or upregulation of sodium channels $(43,44)$. Thus, the increased sensitivity of neuromas to norepinephrine may in part explain the exacerbation of phantom pain by stress and other emotional states associated with increased catecholamine release from sympathetic efferent terminals which are in close proximity to afferent sensory nerves and sprouts (40). It was shown that cell bodies in the dorsal root ganglion show similar abnormal spontaneous activity and increased sensitivity to mechanical and neurochemical stimulation (45). Thus, abnormal activity from neuromas and dorsal root ganglion cell bodies may contribute to the phantom limb percept, including pain.

The second mechanism is considered to be at the spinal cord level. The increased barrage from neuromas and from dorsal root ganglia cells is thought to induce long-term changes in central projecting neurons in the dorsal horn, including spontaneous neuronal activity, induction of immediate early genes, increases in spinal cord metabolic activity, and expansion of receptive fields (46, 47). Nikolajsen and Jensen (40) described that the pharmacology of spinal sensitization involves increased activity in $\mathrm{N}$ methyl-D-aspartate (NMDA) receptoroperated systems (48), and many aspects of the central sensitization can be reduced by NMDA receptor antagonists. This was further confirmed in human amputees with one aspect of such central sensitization, the evoked stump or phantom pain produced by repetitive stimulation of the stump by non-noxious pin prick,

\section{Table 1. Clinical observations of phantom limb pain}

Phantom limb sensations can be modulated by various stump manipulations.

Phantom limb sensations are temporarily abolished after local stump anesthesia.

Stump revisions and removal of tender neuromas often reduce pain, at least transiently.

Phantom pain is significantly more frequent in those amputees with long-term stump pain than in those without persistent pain.

Although obvious stump pathology is rare, altered cutaneous sensibility in the stump is a common if not universal feature.

Changes in stump blood flow alter the phantom limb perception.

Adapted from Nikolajsen and Jensen (40) reduced by the NMDA receptor antagonist ketamine (49). Besides functional changes in the dorsal horn, an anatomical reorganization also has been described (50). It has been shown that peripheral nerve transection results in a substantial degeneration of afferent $\mathrm{C}$-fiber terminals in lamina II, thus reducing the number of synaptic contacts with second-order neurons in lamina II, which normally respond best to noxious stimulation. Consequently, central terminals of $A \beta$ mechanoreceptive afferents, which normally terminate in deeper laminae, sprout into lamina II and may form synaptic contacts with vacant nociceptive second-order neurons. As a result of this organization, evocation of pain is seen with simple touch, etc., by $\mathrm{A} \beta$-fiber input.

The third step in the process is the supraspinal or central mechanism. Based on peripheral and spinal cord mechanisms, it is reasonable to assume that amputation not only produces a cascade of events in the periphery and in the spinal cord, but these changes eventually sweep more centrally and alter neuronal activity in cortical and subcortical structures. It has been shown that thalamic stimulation results in phantom sensation and pain in amputees (51). This suggests that plastic changes in the thalamus are involved in the generation of chronic pain, as normally such stimulation does not evoke pain. Other studies in humans have documented a cortical reorganization after amputation using multiple cerebral imaging techniques (52-67).

Finally, psychological theories have been forwarded as the explain phantom pain. While a biopsychosocial mechanism may be involved in the development and persistence of phantom pain, no consistent pattren of personality disorders or clinical syndromes have been shown to be increased in patients with phantom limb pain. However, psychological disturbances related to the loss of a limb or feelings of dependence, as well chronic pain and disability, may lead to a host of psychological problems in these patients (6873). Patients reporting phantom limb pain have been shown to be more rigid, compulsive, and self-reliant than their cohorts (14).

Etiology of stump pain is often associated with definite pathological findings that may account for the pain in the stump and/or the phantom limb, such as skin pathology, circulatory disturbances, 
Table 2. Classification of patients with phantom pain

\begin{tabular}{|c|c|}
\hline Group I: & $\begin{array}{l}\text { mild, intermittent paraesthesias that do not interfere with normal activity, work, } \\
\text { or sleep. }\end{array}$ \\
\hline Group II: & $\begin{array}{l}\text { paraesthesias that are uncomfortable and annoying but do not interfere with } \\
\text { activities or sleep. }\end{array}$ \\
\hline Group III: & $\begin{array}{l}\text { pain that is of sufficient intensity, frequency, or duration to be distressful; } \\
\text { however, some patients in Group III have pain that is bearable, that intermittently } \\
\text { interferes with their lifestyle, and that may respond to conservative treatment. }\end{array}$ \\
\hline & nearly conctant cevere nain that interfo \\
\hline
\end{tabular}

Adapted from Sunderland (76)

infection of the skin or underlying tissue, bone spurs, or neuromas. However, stump pain and phantom pain may occur without obvious stump pathology.

Multiple risk factors identified for phantom pain include phantom sensations, stump pain, pain prior to the amputation, cause of amputation, prosthesis use, and years elapsed since amputation (74). The most important risk factors for phantom pain were "bilateral amputation" and lower limb amputation." The risk for phantom pain ranges from 0.33 for a 10 -year old patient with a distal upper limb amputation to 0.99 for a subject of 80 years with a bilateral lower limb amputation, of which one side is an above the knee amputation. Van der Schans et al (75) showed that amputees with phantom pain had a poorer health-related quality of life than amputees without phantom pain. Sunderland (76), based on the frequency and severity of pain and the degree to which pain interferes with the patient's lifestyle, proposed a classification to divide patients into four groups ( Table 2).

The usual course of phantom limb pain is to remain unchanged or to improve $(4,27,31)$. Up to $56 \%$ of patients report improvement or complete resolution (27). Ehde et al (21) classified 72\% of patients with phantom limb pain into two low pain-related disability categories: Grade I, low disability/low pain intensity $(47 \%)$ or grade II, low disability/high pain intensity $(28 \%)$. Many participants reported having pain in other anatomic locations, including the back (52\%).

\section{Clinical Presentation}

Phantom sensations are painless. Patients generally describe the sensations in their phantom limb either as normal in character or as pleasant warmth and tingling (4). The strongest sensations come from body parts with the highest brain cortical representation, such as fingers and toes $(4,7,77)$. The phantom limb may undergo "telescoping," in which the patient loses sensations from the midportion of the limb, with subsequent shortening of the phantom (25). During telescoping, the last body parts to disappear are those with the highest representation in the cortex, such as the thumb, index finger, and big toe. Telescoping occurs only with painless phantoms, and it is most common in the upper extremity. However, lengthening of the phantom may occur if pain returns.

Distal parts of the missing limb are primary sites of phantom pain (14, $22,25-27,31,78-82)$. Pain is usually intermittent. A few patients may present with constant pain. Symptom manifestation ranges from daily or weekly intervals, with only a few reporting monthly or yearly, or rare episodes. Individual attacks may last from seconds to hours, but rarely days or longer.

The pain is usually described as burning, aching, or cramping $(30,83)$. Other descriptors include crushing, twisting, grinding, tingling, drawing, stabbing with needles, knifelike, sticking, burning, squeezing, sharp, shocklike, or excruciating, etc. $(27,30,31,35,83)$.

\section{Location and Character} pre-amputation $(27,79)$. The frequency with which pre-amputation pain persists as phantom pain is highly variable from $12.5 \%$ to $80 \%(14,28,31,37,79)$. Several authors have considered pre-amputation pain as a risk factor for phantom pain (24, $43,80,85)$, while others have contradicted it $(22,28,86)$.

Phantom pain may be modulated by multiple factors, both internal as well as external. Exacerbations of pain may be produced by trivial, physical, or emotion stimuli. Anxiety, depression, urination, cough, defecation, sexual activity, cold environment, or changes in the weather may
Phantom pain often may mimic worsen phantom limb pain $(25,26,28,30$, $31,39,83,87)$. It also has been reported that general, spinal, or regional anesthesia in amputees may cause appearance of phantom pain in otherwise pain free subjects $(77,88-92)$.

In contrast to phantom pain, stump pain is often located in the stump itself and often described as either pressing, throbbing, burning, or squeezing (87). Other descriptions have included stabbing sensation or an electrical current. An additional variant involves complaints of spontaneous movements of the stump ranging from painful, hardly visible myoclonic jerks to severe clonic contractions lasting as long as two days.

\section{Physical Examination}

Physical examination is not very useful except for palpating the trigger points in the stump to reproduce the phantom limb pain. Physical examination may reveal altered sensitivity in the stump. Neuromas are found in only $20 \%$ of patients. The amputated limbs may be cold and thermography may be a useful diagnostic test if symptoms consistent with reflex sympathetic dystrophy are present. Sherman et al (48) demonstrated an inverse relationship between pain intensity and skin temperature in patients who described burning, throbbing, or tingling in the phantom limb or stump.

\section{Differential Diagnosis}

The usual course of phantom limb pain is to remain unchanged or to improve gradually. It has been shown that up to $56 \%$ of patients report improvement or even complete resolution (27). Thus, if symptoms of phantom limb pain increase in severity or they start after long periods of time after amputation, a differential diagnosis must be entertained. Multiple causes, which may increase phantom limb pain other than the changes in the weather, autonomic stimulation, etc., include radicular pain, angina, post herpetic neuralgia, and metastatic cancer.

- Radicular pain in the phantom limb may be associated with disc herniation (93)

- Increased levels of pain in the phantom limb may be triggered by new onset herpes zoster or reactivation of herpes zoster by suppressed immunological mechanisms $(94,95)$ 
- Angina may be presented as exacerbated phantom limb pain $(96$ 97)

- Finally, in patients undergoing amputation secondary to malignant disease, if phantom limb pain increases significantly, metastatic disease should be evaluated.

\section{MANAGEment}

Treatment of phantom limb pain or stump pain is difficult and has generally not been very successful. Halbert et al (98) conducted a systematic review to evaluate the evidence for the optimal management of acute and chronic phantom pain. They concluded that there is currently a gap between research and practice in the area of phantom limb pain. Nevertheless, in the past decade, clinical trials have examined treatments for phantom limb pain. Surveys suggest that although physicians believe treatments are effective (99), fewer than $10 \%$ of patients with phantom limb pain receive lasting relief from prescribed medical treatments (27). Even then, clinicians have been restricted by the lack of clinical trials that would aid in treatment decisions and by the absence of evidence-based treatment guidelines. In a literature review in 1980, 43 methods for treating phantom limb pain were identified. However, it was concluded that few produced relief and that placebo responses were common (100). Multiple authors also have recommended treatment for phantom limb pain in line with the management of neuropathic pain states (101103). However, literature review suggests that trials of treatments for neuropathic pain rarely included patients with phantom limb pain.

Early trials concentrated on reduction of established postoperative phantom limb pain, but newer approaches have used analgesic agents administered before amputation (104). Treatment approaches continue to be based on the assumption that long-term phantom limb pain is the result of functional or structural changes in the central nervous system in response to noxious somatosensory input (105). Thus, therapies are directed at early reduction of pain.

Halbert et al (98) noted that their review was limited by the poor quality of the included trials. While they identified 186 articles, they were able to utilize only 12 trials. Of the 12 trials, only 3 randomized, controlled studies with parallel groups and 3 randomized cross-over trials were identified. They also mentioned particular challenges associated with examining phantom limb pain, with an extremely low rates of amputations, high mortality rates among the amputees, and finally, interventions designed to examine operative and perioperative treatments may be ethically unacceptable.

\section{Prevention}

An increasing knowledge about the mechanisms involved in the development and perpetuation of neuropathic pain theoretically should allow us a rational approach to its prevention. However, the initially hopeful attempts like the use of pre and postsurgical epidural blockade have been questioned and its real utility now appears to be controversial (106). Advances in neuroimaging techniques are just now unveiling some keys to the problem. The current emphasis is put on the adaptive processes taking place in the central nervous system following a deafferentation. In this sense, it seems that our ability to prevent post-amputation pain will depend on our capability to modulate the plasticity of the central nervous system. Feria (106) suggested that the problem needs a broad-based approach including control of perioperative pain and inflammation, adequate follow-up of the patients, correct surgical technique, longterm rehabilitation, and the use of pharmacological and behavioral approaches reflecting current knowledge.

Multiple authors have attempted psychological preparation, drug therapy, epidural anesthesia, and regional nerve blocks, among others, to reduce the occurrence of phantom limb pain and to delay or stop the process of progressing from acute to chronic pain. At least some of the postamputation pain may be prevented by appropriate psychological preparation of the patients.

\section{Epidural Anesthesia}

Gehling and Tryba (107) showed that pre-, intra-, and postoperative epidural anesthesia was associated with a significant reduction of phantom limb pain 12 months after amputation. However, they concluded that a reduction of phantom limb pain by postoperative epidural anesthesia alone could not be confirmed on the basis of the analyzed data. They concluded that perioperative epidural anesthesia has been shown to be an effective prophylaxis of phantom limb pain. However, perioperative epidural anesthesia does not completely abolish phantom limb pain, but increases the number of patients with a mild form of phantom pain.

Investigators in 4 trials (108-111) assessed preoperative epidural pain relief and were unable to provide definitive evidence to support its routine use. The results of two studies involving a small number suggested that epidural analgesia may help but were inconsistent: one showed relief at 7 days, 6 months, and 1 year postoperatively (109), the second study (108) showed less phantom limb pain in the intervention group at 1 week, 6 months, and 1 year, and the difference reached significance only at 6 months. The largest of the studies (110) showed no difference in phantom pain at 7 days, 3 months, 6 months, and 12 months. In a randomized prospective study by Lambert et al (111), 30 patients scheduled for lower limb amputation were randomly assigned epidural bupivacaine or an intraoperatively placed perineural catheter for intra and postoperative administration of bupivacaine. All patients had general anesthesia. The results showed there was no significant difference between perioperative epidural block and perineural infusion of local anesthetic. Phantom pain after 3 days in the epidural group was $29 \%$, at 6 months it was $63 \%$, and at 12 months it was $38 \%$. Thus, it is not known whether epidural anesthesia reduced the prevalence of phantom limb pain.

\section{Regional Anesthesia}

Multiple trials have assessed perineural (111-113), and intraneural (114) bupivacaine blocks, either at the time of surgery or immediately postoperatively. Despite some early benefits, there was no difference in pain between the intervention and control groups in the postoperative period $(112,113)$. Perineural block was similar to infusion of local anesthetic through an epidural catheter (111). Evaluation of continuous brachial plexus analgesia showed prevention of phantom limb pain, which did not reappear during follow-up of 1 year (115). Nerve sheath catheter analgesia also showed reduced prevalence (116). 


\section{Other Interventions}

Other treatments assessed for prevention of phantom limb pain included administration of calcitonin, ketamine, intervenous lidocaine, and transcutaneous electrical nerve stimulation (117-121). Intravenous calcitonin in one study (121) evaluating 8 patients showed that only 2 of 8 patients developed phantom limb pain after 10 days of intravenous treatment with salmon calcitonin, with prevalence of phantom limb pain remaining at $25 \%$ in systematic follow-up at 3,6 , and 12 months. However, in another study (117), intravenous calcitonin reduced phantom limb pain in the early postoperative period, but phantom limb pain on longer-term follow-up was not adequately controlled. The effectiveness of ketamine was studied in a prospective, observational study with historical controls with 14 patients in each group (120). However, the results showed that phantom limb pain remained high at $72 \%$, even though only $9 \%$ of the patients after ketamine compared to $71 \%$ of the patients in the control group, complained of severe phantom limb pain. Transcutaneous electrical nerve stimulation was assessed in the 2-week postoperative period, with the treated group reporting less pain at 4 weeks (118). However, by 12 months, there was no difference between the groups.

\section{Pain Management}

\section{Drug Therapy}

Medical therapy is the most commonly utilized modality of treatment for phantom pain syndromes. The most commonly used classes of medications are anti-depressants and anti-convulsants. A large number of randomized, controlled clinical trials have shown a beneficial effect of tricyclic anti-depressants and sodium channel blockers under different neuropathic pain conditions. Even though no controlled trials in phantom pain have been performed, the drugs are generally considered to be effective - at least in some patients (122-127). Tricyclic antidepressants have been thoroughly studied in other denervation syndromes, such as post herpetic neuralgia and diabetic neuropathy (125). However, there have been no studies of their use in treatment of phantom limb pain specifically.

Canovas et al (122) assessed the analgesic effectiveness and tolerance of ami- triptyline versus nefazodone for the management of neuropathic pain. Of the 120 patients included in this study, less than 10 patients suffered with phantom limb pain. The quality of pain was burning and cutting in $62.3 \%$ of the cases, lancinating in $40 \%$, and sharp in $25 \%$. The results showed that after 3 months of therapy, the amitriptyline group showed a pain severity of $2 \pm 0.9$ and in nefazodone group, $3 \pm$ 1.1. Pain relief was greater than $75 \%$ (excellent) in 42 patients treated with amitriptyline and in 36 patients treated with nefazodone, between $50 \%$ to $75 \%$ (good) in 18 patients treated with amitriptyline and in 12 patients treated with nefazodone, and below $50 \%$ (poor) in 3 patients treated with amitriptyline and 3 patients treated with nefazodone. They concluded that both drugs were effective for the management of neuropathic pain. The group treated with nefazodone showed least incidence of side effects, except for nausea and vomiting. The amitriptyline group showed a significant incidence of orthostatic hypotension, dry mouth, nausea, and vomiting.

Historically, carbamazepine is the most commonly used anti-convulsant $(126,127)$. Elliott et al (126) and Patterson (127) reported cases of lancinating phantom limb pains that improved with oral carbamazepine. Logan (128) reported incomplete relief with carbamazepine but complete relief with chlorpromazine in long-standing phantom limb pain. There is no evidence that carbamazepine is effective for pains that are not of the intense, brief, lancinating type.

Currently, gabapentin is the most commonly anti-convulsant used for phantom limb pain. Other than sedation, side effects are rare and patients become tolerant to sedation with time. Since there is no known long-term toxicity, monitoring of blood levels, as with other anti-convulsants is not necessary. The effectiveness of gabapentin in postamputation phantom limb pain was studied in a randomized, double-blind, placebo-controlled, cross-over study by Bone et al (129). They evaluated analgesic efficacy of gabapentin in phantom limb pain in patients attending a multidisciplinary pain clinic. Each treatment was for 6 weeks separated by a 1 -week washout. The daily dose of gabapentin was titrated in increments of 300 $\mathrm{mg}$ to $2400 \mathrm{mg}$ or the maximum tolerated dose. Nineteen eligible patients were randomized, of whom 14 completed both arms of the study. Both placebo and gabapentin treatments resulted in reduced VAS scores compared with baseline. However, the pain intensity difference was significantly greater than placebo for gabapentin therapy at the end of the treatment. They concluded that after 6 weeks, gabapentin monotherapy was better than placebo in relieving postamputation phantom limb pain. There were no significant differences in mood, sleep interference, or activities of daily living. Serpell et al (130) evaluated the use of gabapentin in neuropathic pain in a randomized, doubleblind, placebo-controlled trial of 305 patients in a wide range of neuropathic pain syndromes, including phantom limb pain in $2 \%$ of these patients. They concluded that at an average dose of $900 \mathrm{mg}$ to 2400 mg per day, gabapentin was well tolerated and was associated with significant pain control with few secondary effects - dizziness and somnolence, most of which were transient and occurred during the titration phase.

Analgesic effects of intravenous lidocaine and morphine on postamputation pain were evaluated in a randomized double-blind, active placebo-controlled, cross-over trial by Wu et al (119) An intravenous bolus followed by an intravenous infusion of morphine, lidocaine, and the active placebo (diphenhydramine), were performed on three consecutive days. The results showed that 31 of 32 subjects enrolled completed the study. Eleven subjects had both stump and phantom pains, 11 and 9 subjects had stump and phantom pain alone, respectively. They concluded that stump pain was diminished both by morphine and lidocaine, while phantom pain was diminished only by morphine, suggesting that the mechanisms and pharmacological sensitivity of stump and phantom pains are different.

The effect of an NMDA receptor antagonist have been examined in different studies $(51,131-134)$. In a double-blind, placebo-controlled study, intravenous ketamine reduced pain, hyperalgesia, and "wind-up" like pain in 11 amputees with stump and phantom pain (52). In another controlled trial by the same authors (132), 19 patients received memantine, an NMDA receptor antagonist available for oral use, in a blinded, placebo-controlled, cross-over fashion. Memantine failed to have any effect on spontaneous pain, allodynia, and hyperalgesia. In another randomized, double-blinded, placebo-con- 
trolled trial (134), memantine failed to demonstrate a significant clinical benefit of the NMDA receptor antagonist in chronic phantom limb pain.

Beta-adrenergic blockers have also been suggested for treatment of phantom limb pain based on three cases (135). However, in a double-blind cross-over trial of propranolol up to $240 \mathrm{mg}$ daily, the authors were unable to show significant improvement in post-traumatic neuralgias (136).

Salmon calcitonin has been shown to provide analgesic effect in a series of painful conditions, including phantom limb pain (117, 137-139). However, there are no controlled trials available to show the effectiveness of calcitonin in chronic phantom limb pain. Dextromethorphan was studied for attenuation of phantom pain in cancer amputees in a double-blind cross-over trial involving 3 patients (140). Results showed that oral dextromethorphan effectively reduced postamputation phantom limb pain, bestowing improvement in feeling and minimizing sedation in comparison with the pre-treatment or placebo conditions, with no side effects. Capsaicin also was tried in phantom limb pain $(141,142)$. In this study, which was done in a double-blind fashion with 24 patients, the authors concluded that capsaicin may be used as an alternative treatment for the phantom limb pain. Some have reported a beneficial effect of benzodiazepines (143) however, the general impression is that benzodiazepines do not produce substantial pain relief. Mexiletine (the oral congener of lidocaine) also has been reported to be effective (144).

Finally, opioid analgesics with or without other drugs are considered as the mainstay of treatment in modern medicine. Generally, it is quoted in textbooks that narcotic analgesics are not effective in producing long-term pain relief in patients with phantom limb pain (27). However, modern evidence suggests that opioids can be used safely for years with a limited risk of drug dependence $(4,27,43$, 66, 102, 145-147). Further, patients undergoing amputation related to systemic medical diseases have only a $42 \% 5$-year survival rate, thus the risk of opioid addiction may be weighed against qualityof-life issues (36). In a review of five patients, a $50 \%$ to $90 \%$ reduction in pain at 12 to 26 months was reported with methadone 10 to $20 \mathrm{mg}$ per day (146). In a placebo-controlled trial (66), morphine was shown to reduce pain significantly.

\section{Neural Blockade}

Nerve blocks are commonly used in the treatment of phantom limb pain, and physicians performing these blocks report a high success rate, though it has not been substantiated (99). These range from trigger point injections to neurolytic sympathetic blocks with stump injections, sympathetic blocks, peripheral nerve blocks, and epidural or subarachnoid blocks. However, it has been shown that only $14 \%$ of patients with phantom limb pain report even a significant temporary change, whereas less than $5 \%$ report a large permanent change or cure (27). The use of neural blockade in the treatment of phantom limb pain is largely based on anecdotal reports in the literature (148-150).

Blankenbaker (148) reported that sympathetic blocks are successful if amputees are treated soon after the onset of phantom limb pain. Halbert et al (98) in a systematic review to evaluate evidence for the optimal management of acute and chronic phantom pain was unable to find any trials that met criteria for inclusion.

Lesions of the dorsal root entry zone have been reported to provide long-term pain relief in patients with phantom limb pain following avulsion of nerve roots or amputation $(83,151,152)$. It has been reported that $36 \%$ of patients had pain relief on follow-up at 6 months to 4 years following dorsal root entry zone lesions $(83,152)$. However, they reported very poor relief in patients with stump pain alone.

\section{Neurostimulation}

Transcutaneous electrical nerve stimulation (TENS) has been used with some success in the treatment of phantom pain. However, the results are inconclusive and not encouraging and inconclusive. Spinal cord stimulation (SCS), deep brain stimulation (DBS) of the thalamic nucleus ventralis caudalis, and motor cortex stimulation (MCS) are all used in managing phantom limb pain with variable success.

Some authors have reported excellent relief with transcutaneous electrical nerve stimulation. One author reported success in 5 of 6 patients with phantom pain following treatment with transcutaneous electrical nerve stimulation (153). Another author reported a $66 \%$ reduction in pain lasting less than 10 hours (154) Yet, other authors reported good to excellent results in only $25 \%$ of the patients treated with TENS (155). Stimulation of the contralatateral extremity with TENS also has been shown to have a favorable response in some patients $(156,157)$.

Recent evaluations of spinal cord stimulation have shown encouraging results in neuropathic pain, including reflex sympathetic dystrophy $(158,159)$. Thus, stimulation of posterior columns of the spinal cord is the most common neurosurgical technique used for the treatment of phantom limb pain. The selection process is crucial. Response to transcutaneous stimulation or percutaneous electrical stimulation may predict a response to dorsal column stimulation (160). However, even with appropriate patient selection, it has been reported that only $65 \%$ of the patients receive a greater than $25 \%$ reduction in pain immediately after surgical implantation (161). Further, the success rate of dorsal column stimulation steadily declines over time, and greater than $50 \%$ long-term pain reduction is present in only one-third of patients originally showing improvement $(162,163)$. Spinal cord stimulation may not be effective with pain or phantom limb sensations. In one case report, it was shown that good to excellent results were observed in five patients, as judged by decreased pain and increased functional status with decrease in medication (164). However, in another report, dorsal column stimulation provided minimal relief in patients with phantom limb pain (165). Another report showed that dorsal column stimulation provided improvement in only $25 \%$ of the patients (166). Thus, one should weigh the risk-benefit ratio with caution and diligence.

Intracranial neurostimulation demonstrated initial pain relief in $80 \%$ of patients with sensory thalamic stimulation (167) and $86 \%$ had significant relief with deep brain stimulation (168) Thalamic stimulation, in contrast to spinal cord stimulation, may block spontaneous neuronal activity, which has been proposed to mediate phantom sensation in some models (54). Thus, some believe that it may be more effective than spinal cord stimulation, however, it has not been proven thus far. Percutaneous stimulation of the periosteum has been used, even though it has not been well studied (169). 


\section{Neurosurgical Techniques}

Some have reported multiple neurosurgical techniques apart from electrical stimulation, including intrathecal implantables, stereotactic thermocoagulation lesions, and cordotomy. Some of these treatments may have more serious complications than benefits $(26,170)$. Sporadic success has been reported with many physical therapy modalities including ultrasound or vibration, heat or cold, massage therapy, or stump percussion (99).

It was noted that neither surgeons nor patients reported good success rates with currently recommended surgical procedures $(27,99)$.

\section{Stump Revision}

Patients with continued phantom limb pain and also issues related to the stump with vascular insufficiency, infection, or extensive neuromas may undergo stump revision, which may benefit $50 \%$ of the patients (30).

\section{Physical Therapy}

Physical therapy has been shown to be useful, especially the educational aspect with attention to the stump and preparation for prosthesis, as phantom limb pain is most commonly seen in patients who are unable to use a prosthesis within six months following amputation.

\section{Acupuncture}

Acupuncture has shown to provide relief from phantom limb pain of the arm with electroacupuncture (171). Mostly, short-term relief has been reported with the first few acupuncture treatments, however no long improvement in patients with a history of nerve damage, including phantom limb pain has been reported (172).

\section{Electroconvulsive Therapy}

A case report of electroconvulsive therapy with study of regional cerebral blood flow (173) suggested that total resolution of pain in this particular patient and the regional cerebral blood flow of the anterior cingulate cortex and insula were related to the analgesic effectiveness of ECT. In another case report (174), the authors reported two patients with severe phantom limb pain refractory to multiple therapies, without concurrent psychiatric disorder, enjoying substantial pain relief of phantom pain on long-term follow-up at 3.5 years.

\section{Psychological Therapies}

Multiple psychological modalities have been attempted in managing phantom limb pain $(68,175-181)$. Psychotherapy was reported to yield good results (68). Relaxation training with or without biofeedback or hypnosis has been studied (175-181). It has been reported that in 12 of the 14 patients with chronic phantom limb pain, significant improvement was noted with muscular relaxation training to disrupt the pain-anxiety-tension cycle (175). In this study, patients required an average of six treatments to produce therapeutic effect and it was also associated with decreased anxiety levels and increased pain relief. In a case report, combined EMG and thermal biofeedback was shown to be effective in a patient with extreme phantom limb pain at 12-month follow-up. Hypnotic suggestion of stocking-glove anesthesia may lead to a reduction in phantom limb pain $(177,178)$. It was shown that $45 \%$ of the patients were successfully hypnotized, and $35 \%$ had successful improvement in phantom limb pain (180). However, relapses occurred soon after the discontinuation of the treatment in $34 \%$ of the patients. In a case report describing two patients utilizing hypnotic imagery as a treatment for phantom limb pain (179), the authors concluded that hypnotic procedures appear to be a useful adjunct to establish strategies for the treatment of phantom limb pain.

\section{Conclusion}

Phantom pain syndromes are a common consequence of removal of a limb or other organ. Approximately two-thirds of patients complain of phantom pain following the removal of a limb. However, in less than $10 \%$ of the patients, pain presents as a severe incapacitating condition. The understanding of phantom limb pain has improved substantially in the past two decades with a series of morphological, physiological, and biological changes resulting in hyperexcitability in the nervous system based on experimental studies. Medical and surgical approaches for the prevention or treatment of phantom pain are in their infancy and not well studied. At present, there is no evidence-based approach for the management of phantom pain syndromes.

\section{Author Affiliation: \\ Laxmaiah Manchikanti, MD \\ Medical Director \\ Pain Management Center of Paducah \\ 2831 Lone Oak Road \\ Paducah, Kentucky 42003 \\ E-mail: drm@apex.net. \\ Vijay Singh, MD \\ Medical Director \\ Pain Diagnostics Associates \\ 1601 Roosevelt Road, Niagara, Wis- \\ consin 54151 \\ E-mail vijsin@netscap.net}

\section{References}

1. Keynes G. The Apologie and Treatise of Ambroise Paré. Chicago, University of Chicago Press, 1952.

2. Keil G. Sogenannte erstbeschreibung des phantomschmerzes von Ambroise Paré. Fortschritte der medicine 1990; 108:5866.

3. Mitchell SW. Injuries of Nerves and Their Consequences. London, Smith, Elder, 1872.

4. Hord AH, Shannon C. Phantom Pain. In Raj PP (ed.) Practical Management of Pain $3^{\text {rd }}$ ed. Philadelphia, Mosby, Inc., 2000, pp 212-222.

5. Hanowell ST, Kennedy SF. Phantom tongue pain and causalgia: Case presentation and treatment. Anesth Analg 1979; 58: 436-438.

6. Jamison $\mathrm{K}$, Wellisch DK, Katz RL et al. Phantom breast syndrome. Arch Surg 1979; 114:93-95.

7. Rothemund Y, Grüsser SM, Liebeskind U et al. Phantom phenomena in mastectomized patients and their relation to chronic and cute pre-mastectomy pain. Pain 2004; 107:140-146.

8. Cherng $\mathrm{CH}$, Wong CS, Ho ST et al. Prevalence and clinical characteristics of phantom rectum syndrome after rectum resection in Chinese patients. Pain Clinic 2001; 13:113-117.

9. Biley FC. Phantom bladder sensations: A new concern for stoma care workers. $\mathrm{Br} J$ Nurs 2001; 10:1290-1296.

10. Thomas CR, Brazeal BA, Rosenberg L et al. Phantom limb pain in pediatric burn survivors. Burns 2003; 29:139-142.

11. Simmel ML. Phantoms in patients with leprosy and in elderly digital amputees. Am J Psychol 1956; 69:529-545.

12. Parkes CM. Factors determining the persistence of phantom pain in the amputee. J Psychosom Res 1973; 17:97-108.

13. Gillis L. The management of the painful amputation stump: A new theory for the phantom phenomena. Br/ Surg 1964; 51: 87-95. 
14. Weiss SA, Fishman S. Extended and telescoped phantom limb in unilateral amputees. J Abnorm Soc Psychol 1963; 66:489497.

15. Almagor M, Jaffe $Y$, Lomranz J. The relation between limb dominance, acceptance of disability, and the phantom limb phenomenon. J Abnorm Psychol 1978; 87:377379.

16. Alamo Tomillero F, Rodriguez de la Torre R, Caba Barrientos F et al. Prospective study of prevalence and risk factors for painful phantom limb in the immediate postoperative period of patients undergoing amputation for chronic arterial ischemia. Rev Esp Anestesiol Reanim 2002; 49:295-301.

17. Lacoux PA, Crombie IK, Macrae WA. Pain in traumatic upper limb amputees in Sierra Leone. Pain 2002; 99:309-312.

18. Gallagher P, Allen D, Maclachlan M. Phantom limb pain and residual limb pain following lower limb amputation: A descriptive analysis. Disabil Rehabil 2001; 23: 522-530.

19. Fraser CM, Halligan PW, Robertson IH et al. Characterizing phantom limb phenomena in upper limb amputees. Prosthet Orthot Int 2001; 25:235-242.

20. Araya E, Pernía J, Teran P et al. Phantom limb pain following traumatic upper limb amputation. Cirugia Plastica Ibero-Latinoamericana 2001; 27:159-163.

21. Ehde DM, Czerniecki JM, Smith DG et al. Chronic phantom sensations, phantom pain, residual limb pain, and other regional pain after lower limb amputation. Arch Phys Med Rehabil 2000; 81:1039-1044.

22. Kooijman CM, Dijkstra PU, Geertzen JH et al. Phantom pain and phantom sensations in upper limb amputees: An epidemiological study. Pain 2000; 87:33-41.

23. Wilkins KL, McGrath PJ, Finley GA et al. Phantom limb sensations and phantom limb pain in child and adolescent amputees. Pain 1998; 78:7-12.

24. Hagberg K, Brånemark R. Consequences of non-vascular trans-femoral amputation: A survey of quality of life, prosthetic use and problems. Prosthet Orthot Int 2001; 25:186-194.

25. Jensen TS, Krebs B, Nielsen J et al. Phantom limb, phantom pain and stump pain in amputees during the first 6 months following limb amputation. Pain 1983; 17:243256.

26. Sherman RA, Sherman CJ. Prevalence and characteristics of chronic phantom limb pain among American veterans: Results of a trail survey. Am J Phys Med 1983; 62: 227-238.

27. Sherman RA, Sherman CJ, Parker L. Chronic phantom and stump pain among American veterans: Results of a survey. Pain 1984; 18:83-95.

28. Wall R, Novotny-Joseph P, MacNamara TE. Does preamputation pain influence phantom limb pain in cancer patients? South Med J 1985; 78:34-36.

29. Dijkstra PU, Geertzen JH, Stewart R et al.
Phantom pain and risk factors: A multivariate analysis. J Pain Symptom Manage 2002; 24:578-585.

30. Bailey AA, Moersch FP. Phantom limb. Can Med Assoc J 1941; 45:37-42.

31. Jensen TS, Krebs B, Nielsen J et al. Immediate and long-term phantom limb pain in amputees: Incidence, clinical characteristics and relationship to pre-amputation limb pain. Pain 1985; 21:267-278.

32. Sternbach T, Nadvorna H, Arazi D. A fiveyear follow-up study of phantom limb pain in post-traumatic amputees. Scand J Rehab Med 1982; 14:203-207.

33. Ribera H, Cano P, Dora A et al. Phantom limb pain secondary to post-trauma stump hematoma 40 years after amputation: Description of one case. Revista de la Sociedad Espanola del Dolor 2001; 8:217-220.

34. Rajbhandari SM, Jarett JA, Griffiths PD et al. Diabetic neuropathic pain in a leg amputated 44 years previously. Pain 1999; 83:627-629.

35. Sherman RA, Sherman CJ. A comparison of phantom sensations among amputees whose amputations were of civilian and military origins. Pain 1985; 21:91-97.

36. Helm P, Engel T, Holm A et al. Function after lower limb amputation. Acta Orthop Scand 1986; 57:154-157.

37. Nikolajsen L, Ilkjaer S, Kroner K et al. The influence of pre-amputation pain on postamputation stump and phantom pain. Pain 1997; 72:393-405.

38. Houser SA. Phantom limb pain. In Warfield CA, Fausett HJ (eds.) Manual of Pain Management, 2nd ed. Philadelphia, Lippincott Williams \& Wilkins, 2002, pp 181183.

39. Frazier SH. Psychiatric aspects of causalgia, the phantom limb, and phantom pain. Dis Nerv Syst 1966; 27:441-451.

40. Nikolajsen L, Jensen TS. Postamputation pain. In Melzack R, Wall PD (eds.) Handbook of Pain Management. Edinburgh, Churchill Livingstone, 2003, pp 247-257.

41. Wall PD, Gutnick M. Ongoing activity in peripheral nerves: The physiology and pharmacology of impulses originating from a neuroma. Exp Neurol 1974; 43: 580-593.

42. Devor M, Seltzer Z. Pathophysiology of damaged nerves in relation to chronic pain. In Wall PD, Melzack R (eds.) Textbook of Pain, 4th ed. Edinburgh, Churchill Livingstone, 1999, pp 129-164.

43. Devor M, Govrin-Lippman R, Angelides K. $\mathrm{Na}+$ channels immunolocalization in peripheral mammalian axons and changes following nerve injury and neuroma formation. J Neurosci 1993; 135:1976-1992.

44. Novakovic SD, Tzoumaka E, McGivern JG et al. Distribution of the tetrodotoxin-resistant sodium channel $\mathrm{PN}_{3}$ in rat sensory neurons in normal and neuropathic pain conditions. J Neurosci 1998; 18:21742187.

45. Kajander KC, Wakisaka S, Bennett GJ.
Spontaneous discharge originates in the dorsal root ganglion at the onset of a pain ful peripheral neuropathy in the rat. $\mathrm{Neu}$ rosci Lett 1992; 138:225-228.

46. Price DD, Mao J, Mayer DJ. Central consequences of persistent pain states. Jensen TS, Turner JM, Wiesenfeld-Hallin Z (eds.) In Proceedings of the 8th World Congress on Pain, Progress in Pain Research and Management, Vol. 8. Seattle, IASP Press, 1997, pp 155-184.

47. Cook AJ, Woolf CJ, Wall PD et al. Dynamic receptive field plasticity in rat spinal cord dorsal horn following c-primary afferent input. Nature 1987; 325:151-153.

48. Doubell TP, Mannion RJ, Woolf CJ. The dorsal horn: State-dependent sensory processing, plasticity and the generation of pain. In Wall PD, Melzack R (eds.) Textbook of Pain, 4th ed. Edinburgh, Churchill Livingstone, 1999, pp 165-181.

49. Nikolajsen L, Hansen CL, Nielsen J et al. The effect of ketamine on phantom pain: A central neuropathic disorder maintained by peripheral input. Pain 1996; 67:69-77.

50. Woolf CJ, Shortland P, Coggeshaal RE. Peripheral nerve injury triggers central sprouting of myelinated afferents. Nature 1992; 355:75-78.

51. Davis KD, Kiss ZH, Luo L. Phantom sensations generated by thalamic microstimulation. Nature 1998; 391:385-387.

52. Willoch F, Rosen G, Tolle TR et al. Phantom limb pain in the human brain: Unraveling neural circuitries of phantom limb sensations using positron emission tomography. Ann Neurol 2000; 48:842-849.

53. Mackert BM, Sappok T, Grüsser $\mathrm{S}$ et al. The eloquence of silent cortex: Analysis of afferent input to deafferented cortex in arm amputees. Neuroreport 2003; 14: 409-412.

54. Dettmers C, Adler T, Rzanny R et al. Increased excitability in the primary motor cortex and supplementary motor area in patients with phantom limb pain after upper limb amputation. Neurosci Lett 2001; 307:109-112.

55. Karl A, Birbaumer N, Lutzenberger W et al. Reorganization of motor and somatosensory cortex in upper extremity amputees with phantom limb pain. I Neurosci 2001; 21:3609-3618.

56. Wei F, Zhuo M. Potentiation of sensory responses in the anterior cingulate cortex following digit amputation in the anaesthetised rat. J Physiol 2001; 532:823-833.

57. Flor $\mathrm{H}$. The modification of cortical reorganization and chronic pain by sensory feedback. Appl Psychophysiol Biofeedback 2002; 27:215-227.

58. Huse E, Larbig W, Birbaumer $\mathrm{N}$ et al. Cortical reorganization and pain. Empirical findings and therapeutic implication using the example of phantom pain. Schmerz 2001; 15:131-137.

59. Roux FE, Ibarrola D, Lazorthes $Y$ et al. Chronic motor cortex stimulation for phantom limb pain: A functional magnetic reso- 
nance imaging study: Technical case. Neurosurgery 2001; 48:681-688.

6o. Flor H, Elbert T, Knecht S. Phantom limb pain as a perceptual correlate of cortical reorganization following arm amputation. Nature 1995; 375:482-484.

61. Flor H, Elbert T, Mühlnickel W. Cortical reorganization and phantom phenomena in congenital and traumatic upper-extremity amputees. Exp Brain Res 1998; 119:205212.

62. Birbaumer N, Lutzenberger W, Montoya $P$ et al. Effects of regional anesthesia on phantom limb are mirrored in changes in cortical reorganization in upper limb amputees. J Neurosci 1997; 17:5503-5508.

63. Huse E, Larbig W, Flor $\mathrm{H}$ et al. The effect of opioids on phantom limb pain and cortical reorganization. Pain 2001; 90:47-55.

64. Matzer O, Devor M. Contrasting thermal sensitivity of spontaneously active A- and $C$-fibers in experimental nerve-end neuromas. Pain 1987; 30:373-384.

65. Kolb LC. The Painful Phantom. Springfield, Charles C. Thomas, 1954.

66. University of California. Progress Report to the Advisory Committee on Artificial Limbs, $2^{\text {nd }}$ ed. Berkeley, University of California Press, 1952.

67. Ewalt JR, Randall GC, Morris H. The phantom limb. Psychosom Med 1947; 9:118123.

68. Lindesay J. Validity of the general health questionnaire (GHQ) in detecting psychiatric disturbance in amputees with phantom pain. J Psychosom Res 1986; 30:277281.

69. Whyte AS, Niven CA. Psychological distress in amputees with phantom limb pain. J Pain Symptom Manage 2001; 22: 938-946.

70. Sherman RA, Sherman CJ, Bruno GM. Psychological factors influencing chronic phantom limb pain: An analysis of the literature. Pain 1987; 28:285-295.

71. Frazier SH, Kolb LC. Psychiatric aspects of pain and the phantom limb. Orthop Clin North Am 1970; 1:481-495.

72. Ewalt JR. The phantom limb. Ann Intern Med 1956; 44:668-677.

73. Larbig W, Montoya P, Flor $\mathrm{H}$ et al. Evidence for a change in neural processing in phantom limb patients. Pain 1996; 67:275283.

74. Loeser JD. Pain after amputation: Phantom limb and stump pain. In Bonica JJ (ed.) The Management of Pain, 2nd ed. Philadelphia, Lea \& Febiger, 1990, pp 244256.

75. Van der Schans CP, Geertzen JH, Schoppen $\mathrm{T}$ et al. Phantom pain and health-related quality of life in lower limb amputees. J Pain Symptom Manage 2002; 24: 429-436.

76. Sunderland S. Nerves and Nerve Injuries. New York, Churchill Livingstone, 1978.

77. Miles JE. Phantom limb syndrome occurring during spinal anesthesia: Relation- ship to etiology. J Nerv Ment Dis 1956; 123:365-368.

78. Carlen PL, Wall PD, Nadvorna $\mathrm{H}$ et al. Phantom limbs and related phenomena in recent traumatic amputations. Neurology 1978; 28:211-217.

79. Katz J, Melzack R. Pain 'memories' in phantom limbs: Review and clinical observations. Pain 1990; 43:319-336.

8o. Krane EJ, Heller LB. The prevalence of phantom sensation and pain in pediatric amputees. J Pain Symptom Manage 1995; 10:21-29.

81. Wartan SW, Hamann W, Wedley JR et al. Phantom pain and sensation among British veteran amputees. Br J Anaesth 1997; 78:652-659.

82. Montoya P, Larbig W, Grulke N. Relationship of phantom limb pain to other phantom limb phenomena in upper extremity amputees. Pain 1997; 72:87-93.

83. Saris SC, lacono RP, Nashold BS Jr. Dorsal root entry zone lesions for post-amputation pain. J Neurosurg 1985; 62:72-76.

84. Appenzeller O, Bicknell JM. Effects of nervous system lesions on phantom experience in amputees. Neurology 1969; 19: 141-146.

85. Houghton AD, Nicolls G, Houghton $A L$ et al. Phantom pain: Natural history and association with rehabilitation. Ann $R$ Coll Surg Engl 1994; 76:22-25.

86. Henderson WR, Smyth GE. Phanton limbs. J Neurol Neurosurg Psych 1948; 11:88-112.

87. Sherman RA, Barja RH, Bruno GM. Thermographic correlates of chronic pain: Analysis of 125 patients incorporating evaluations by a blind panel. Arch Phys Med Rehabil 1987; 68:273-279.

88. Mackenzie N. Phantom limb pain during spinal anaesthesia. Recurrence in amputees. Anaesthesia 1983; 38:886-887.

89. Martin G, Grant SA, MacLeod DB et al. Severe phantom leg pain in an amputee after lumbar plexus block. Reg Anesth Pain Med 2003; 28:475-478.

90. Murphy JP, Anandaciva SP. Phantom limb pain and spinal anesthesia. Anaesthesia 1984; 39:188.

91. Sellick BC. Phantom limb pain and spinal anesthesia. Anesthesiology 1985; 62:801802.

92. Lee ED, Donovan K. Reactivation of phantom limb pain after combined interscalene brachial plexus block and general anesthesia: Successful treatment with intravenous lidocaine. Anesthesiology 1995; 82: 295-298.

93. Finneson BE, Haft H, Krueger EG. Phantom limb syndrome associated with herniated nucleus pulposus. J Neurosurg 1957; 14: 344-346.

94. Wilson PR, Person JR, Su DW et al. Herpes zoster reactivation of phantom limb pain. Mayo Clin Proc 1978; 53:336-338.

95. Sugarbaker PH, Weiss CM, Davidson DD et al. Increasing phantom limb pain as a symptom of cancer recurrence. Cancer
1984; 54:373-375.

96. Cohen H. Anginal pain in a phantom limb. BrMed J 1976; 2:475.

97. Mester SW, Cintron GB, Long C. Phantom angina. Am Heart J 1988; 116:1627-1628.

98. Halbert J, Crotty M, Cameron ID. Evidence for optimal management of acute and chronic phantom pain: A systematic review. Clin J Pain 2002; 18:84-92.

99. Sherman RA, Sherman CJ, Gall NG. A survey of current phantom limb pain treatment in the United States. Pain 1980; 8: 85-99.

100. Sherman R. Published treatments of phantom limb pain. Am J Phys Med 1980; 59:232-244.

101. McQuay H, Carroll D, Jadad AR et al. Anticonvulsant drugs for management of pain: A systematic review. BMJ 1995; 311:10471052.

102. Baron R, Wasner G, Lindner V. Optimal treatment of phantom limb pain in the elderly. Drugs Aging 1998; 12:361-376.

103. Esquenazi A, Meier RH. Rehabilitation in limb deficiency; IV. Limb amputation. Arch Phys Med Rehabil 1996; 77:S18-S28.

104. Katz J. Prevention of phantom limb pain by regional anesthesia. Lancet 1997; 349: 519-520.

105. McQuay HJ, Dickenson AH. Implications of nervous system plasticity for pain management. Anaesthesia 1990; 45:101-102.

106. Feria M. Can we prevent post-amputation pain. DOLOR 2001; 16:73-77.

107. Gehling M, Tryba M. Prophylaxis of phantom pain: Is regional analgesia ineffective? Schmerz 2003; 17:11-19.

108. Bach S, Noreng MF, Tjellden NU. Phantom limb pain in amputees during the first 12 months following limb amputation, after preoperative lumbar epidural blockade. Pain 1988; 33:297-301.

109. Jahangiri M, Jayatunga AP, Bradley JWP et al. Prevention of phantom pain after major lower limb amputation by epidural infusion of diamorphine, clonidine, and bupivacaine. Ann R Coll Surg Engl 1994; 76: 324-326.

110. Nikolajsen L, Ilkjær S, Christensen JH et al. Randomised trial of epidural bupivacaine and morphine in prevention of stump and phantom pain in lower-limb amputation. Lancet 1997; 350:1353-1357.

111. Lambert AW, Dashfield AK, Cosgrove $C$ et al. Randomized prospective study comparing preoperative epidural and intraoperative perineural analgesia for the prevention of postoperative stump and phantom limb pain following major amputation. Reg Anesth Pain Med 2001; 26:316-321.

112. Fisher A, Meller Y. Continuous postoperative regional analgesia by nerve sheath block for amputation surgery-A pilot study. Anesth Analg 1991; 72:300-303.

113. Pinzur M, Garla PG, Pluth T et al. Continuous postoperative infusion of a regional anaesthetic after an amputation of the lower extremity. J Bone Joint Surg Am 
1996; 79:1752-1753.

114. Elizanga AM, Smith DG, Sharar SR et al. Continuous regional analgesia by intraneuronal block: Effect on postoperative opioid requirements and phantom limb pain following amputation. J Rehabil Res Dev 1994; 31:179-187.

115. Keifer RT, Wiech K, Töpfner S et al. Continuous brachial plexus analgesia and NMDA-receptor blockade in early phantom limb pain: A report of two cases. Pain Med 2002; 3:156-160.

116. Morey TE, Giannoni J, Duncan E et al. Nerve sheath catheter analgesia after amputation. Clin Orthop 2002; 397:281-289.

117. Jaeger $\mathrm{H}$, Maier $\mathrm{C}$. Calcitonin in phantom limb pain: A double-blind study. Pain 1992; 48:21-27.

118. Finsen V, Persen L, Lovlien $M$ et al. Transcutaneous electrical nerve stimulation after major amputation. J Bone Joint Surg $\mathrm{Br}$ 1988; 70:109-112.

119. Wu CL, Tella P, Staats PS et al. Analgesic effects of intravenous lidocaine and morphine on postamputation pain: A randomized double-blind, active placebo-controlled, crossover trial. Anesthesiology 2002; 96:841-848.

120. Dertwinkel R, Heinrichs C, Senne I et al. Prevention of severe phantom limb pain by perioperaetive administration of ketamine - An observational study. Acute Pain 2002; 4:9-13.

121. Simanski C, Lempa M, Koch $G$ et al. Therapy of phantom pain with salmon calcitonin and effect on postoperative patient satisfaction. Chirurg 1999; 70:674-681.

122. Canovas L, Martinez-Salgado J, Barros C et al. Management of neuropathic pain: Preliminary study of amitriptyline versus nefazodone. Revista de la Sociedad Espanola del Dolor 2000; 7l:425-430.

123. Iacono RP, Sandyk R, Baumford CR et al. Post-amputation phantom pain and autonomous stump movements responsive to doxepin. Funct Neurol 1987; 2:343348.

124. Sindrup SH, Jensen TS. Efficacy of pharmacological treatments of neuropathic pain: An update and effect related to mechanism of drug action. Pain 1999; 83: 389-400.

125. Getto CJ, Sorkness CA, Howell T. Antidepressants and chronic nonmalignant pain: A review. J Pain Symptom Manage 1987; 2:9-18.

126. Elliott F, Little A, Milbrandt W. Carbamazepine for phantom limb phenomena. $N$ Engl J Med 1976; 295:678.

127. Patterson JF. Carbamazepine in the treatment of phantom limb pain. South Med J 1988; 81:1100-1102.

128. Logan TP. Persistent phantom limb pain: Dramatic response to chlorpromazine. South Med J 1983; 76:1585.

129. Bone M, Critchley P, Buggy DJ. Gabapentin in postamputation phantom limb pain: A randomized, double-blind, placebo-con- trolled, cross-over study. Reg Anesth Pain Med 2002; 27:481-486.

130. Serpell MG, Neuropathic Pain Study Group. Gabapentin in neuropathic pain syndromes: A randomized, double-blind, placebo-controlled trial. Pain 2002; 99: 557-566.

131. Nikolajsen L, Hansen PO, Jensen TS. Oral ketamine therapy in the treatment of postamputation stump pain. Acta Anaesthesiol Scand 1997; 41:427-429.

132. Nikolajsen L, Gottrup H, Kristensen AGD et al. Memantine (a N-methyl D-aspartate receptor antagonist) in the treatment of neuropathic pain following amputation or surgery: A randomized, double-blind, crossover study. Anesth Analg 2000; 91:960966.

133. Stannard CF, Porter GE. Ketamine hydrochloride in the treatment of phantom limb pain. Pain 1993; 54:227-230.

134. Maier C, Dertwinkel R, Mansourian N et al. Efficacy of the NMDA-receptor antagonist memantine in patients with chronic phantom limb pain - Results of a randomized double-blinded, placebo-controlled trial. Pain 2003; 103:277-283.

135. Marsland AR, Weekes JW, Atkinson RL et al. Phantom limb pain: A case for beta blockers? Pain 1982; 12:295-297.

136. Scadding JW, Wall PD, Parry CB et al. Clinical trial of propranolol in post-traumatic neuralgia. Pain 1982; 14:283-292.

137. Appelboom T. Calcitonin in reflex sympathetic dystrophy syndrome and other painful conditions. Bone 2002; 30:84S$86 \mathrm{~S}$.

138. Kessel C, Wörz R. Clinical note: Immediate response of phantom limb pain to calcitonin. Pain 1987; 30:79-87.

139. Gennari C, Francini G, Gonneli S et al. Dolore osseo, endofine e calcitonine. In Gennari C, et al (eds.) The Effects of Calcitonin in Man. Milano, Italy, Masson, 1983.

140. Ben Abraham R, Marouani N, Kollender $Y$ et al. Dextromethorphan for phantom pain attenuation in cancer amputees: A double-blind crossover trial involving three patients. Clin J Pain 2002; 18:282285.

141. Rayner HC, Atkins RC, Westerman RA. Relief of local stump pain by capsaicin cream. Lancet 1989; 2:1276-1277.

142. Atesalp AS, Ozkan Y, Komurcu M et al. The effects of capsaicin in phantom limb pain. Agri 2000; 12:30-33.

143. Bartusch SL, Sanders J, Dálessio JG et al. Clonazepam for the treatment of lancinating phantom limb pain. Clin I Pain 1996; 12:59-62.

144. Davis RW. Successful treatment for phantom pain. Orthopedics 1993; 16:691-695.

145. Dellemijn P. Are opioids effective in relieving neuropathic pain? Pain 1999; 80:453462.

146. Urban BJ, France RD, Steinberger EK et al. Long-term use of narcotic/antidepressant medication in the management of phan- tom limb. Pain 1986; 24:191-196.

147. Bergmans L, Snijdelaar DG, Katz J et al. Methadone for phantom limb pain. Clin J Pain 2002; 18:203-205.

148. Blankenbaker WL. The care of patients with phantom limb pain in a pain clinic. Anesth Analg 1977; 56:842-846.

149. Wassef MR. Phantom pain with probable reflex sympathetic dystrophy. Efficacy of fentanyl infiltration of the stellate ganglion. Reg Anesth 1997; 22:287-290.

150. Lierz P, Schroegendorfer K, Choi S et al. Continuous blockade of both brachial plexus with ropivacaine in phantom pain: A case report. Pain 1998; 78:135-137.

151. Moossy JJ, Nashold BS Jr, Osborne D et al. Conus medullaris nerve root avulsions. J Neurosurg 1987; 66:835-841.

152. Saris SC, lacono RP, Nashold BS Jr. Successful treatment of phantom pain with dorsal root entry zone coagulation. Appl Neurophysiol 1988; 51:188-197.

153. Long DM. Cutaneous afferent stimulation for relief of chronic pain. Clin Neurosurg 1974; 21:257-268.

154. Melzack R. Prolonged relief of pain by brief, intense transcutaneous somatic stimulation. Pain 1975; 1:357-373.

155. Shealy CN. Transcutaneous electrical stimulation for control of pain. Clin Neurosurg 1974; 21:269-277.

156. Winnem MF, Amundsen T. Treatment of phantom limb pain with TENS. Pain 1982; 12:299-300.

157. Carabelli RA, Kellerman WC. Phantom limb pain: Relief by application of TENS to contralateral extremity. Arch Phys Med Rehabil 1985; 66:466-467.

158. Grabow TS, Tella PK, Raja SN. Spinal cord stimulation for complex regional pain syndrome: an evidence-based medicine review of the literature. Clin J Pain 2003; 19: 371-383.

159. Manchikanti L, Staats P, Singh $V$ et al. Evidence-based practice guidelines for interventional techniques in the management of chronic spinal pain. Pain Physician 2003; 6:3-80.

160. Miles J, Lipton S. Phantom limb pain treated by electrical stimulation. Pain 1978; 5: 373-382.

161. Krainick JU, Thoden U, Riechert T. Spinal cord stimulation in post-amputation pain. Surg Neurol 4:167-170, 1975.

162. Krainick JU, Thoden U, Riechert T. Pain reduction in amputees by long-term spinal cord stimulation: Long-term follow-up study over 5 years. J Neurosurg 1980; 52: 346-350.

163. Krainick JU, Thoden U. Spinal cord stimulation in post-amputation pain. In Siegfriend J, Zimmerman $M$ (eds.) Phantom and Stump Pain. New York, Springer, 1981.

164. Nielson KD, Adams JE, Hosobuchi Y. Phantom limb pain: Treatment with dorsal column stimulator. I Neurosurg 1975; 42: 301-307. 
165. Wester K. Dorsal column stimulation in pain treatment. Acta Neurol Scand 1987; 75:151-155.

166. Hunt WE, Goodman JH. Dorsal column stimulation for phantom limb pain. / Neurosurg 1975; 43:250-251.

167. Levy RM, Lamb S, Adams JE. Treatment of chronic pain by deep brain stimulation: Long-term follow-up and review of the literature. Neurosurgery 1987; 21:885-893.

168. Mundinger F, Nermuller H. Programmed transcutaneous (TNS) and central (DBS) stimulation for control of phantom limb pain and causalgia: A new method for treatment. In Siegfriend J, Zimmerman M (eds.) Phantom and Stump Pain. New York, Springer, 1981.

169. Lawrence RM. Persistent limb pain in below-knee amputee. JAMA 1976; 236:822823 .

170. Steinbach TV, Nadvorna H, Arazi D: A five year follow-up study of phantom limb pain in posttraumatic amputees. Scand J Reha bil Med 1982; 14:203-207.

171. Monga TN, Jaksic T. Acupuncture in phantom limb pain. Arch Phys Med Rehabil 1981; 62:229-231.

172. Levine JD, Gormley J, Fields HL. Observations on the analgesic effects of needle puncture (acupuncture). Pain 1976; 2: 149-159.

173. Fukui S, Shigemori S, Komoda Y, et al. Phantom pain with beneficial response to electroconvulsive therapy (ECT) and regional cerebral blood flow (rCBF) studied with xenon-CT. Pain Clinic 2002; 13:355359.

174. Rasmussen KG, Rummans TA. Electroconvulsive therapy for phantom limb pain. Pain 2000; 85:297-299.

175. Sherman RA, Gall N, Gormley J. Treatment of phantom limb pain with muscular relax ation training to disrupt the pain-anxietytension cycle. Pain 1979; 6:47-55.
176. Dougherty J. Relief of phantom limb pain after EMG biofeedback-assisted relaxation: A case report. Behav Res Ther 1980; 18:355-357.

177. Seigel EF. Control of phantom limb pain by hypnosis. Am J Clin Hypnosis 1979; 21: 285-286.

178. Cedercreutz C. Hypnotic treatment of phantom sensations in 100 amputees. Acta Chir Scand 1954; 107:158-162.

179. Oakley DA, Whitman LG, Halligan PW. Hypnotic imagery as a treatment for phantom limb pain: Two case reports and a review. Clin Rehabil 2002; 16:368-377.

180. Belleggia G, Birbaumer N. Treatment of phantom limb pain with combined EMG and thermal biofeedback: A case report. Appl Psychophysiol Biofeedback 2001; 26:141-146.

181. Frischenschlager O, Pucher I. Psychological management of pain. Disabil Rehabil 2002; 24:416-422. 
